\title{
Neuropsychological Rehabilitation of Executive Functions: Challenges and Perspectives
}

\author{
Priscila Dib Gonçalves $^{1-4}$, Mariella Ometto ${ }^{2,3}$, Gabriela Sendoya ${ }^{3}$, Cristine Lacet ${ }^{4}$, \\ Luciana Monteiro ${ }^{5}$, Paulo Jannuzzi Cunha ${ }^{1-3,5}$ \\ ${ }^{1}$ Interdisciplinary Group of Studies on Alcohol and Drugs (GREA), Institute of Psychiatry (IPq), \\ School of Medicine, University of São Paulo (USP), São Paulo, Brazil \\ ${ }^{2}$ Laboratory of Psychiatric Neuroimaging (LIM 21), Department of Psychiatry, School of Medicine, \\ University of São Paulo (USP), São Paulo, Brazil \\ ${ }^{3}$ Center for Interdisciplinary Research on Applied Neurosciences (NAPNA), University of São Paulo (USP), São Paulo, Brazil \\ ${ }^{4}$ Psychology \& Neuropsychology Service, Institute of Psychiatry (IPq), School of Medicine, \\ University of São Paulo (USP), São Paulo, Brazil \\ ${ }^{5}$ Equilibrium Program, Department of Psychiatry, School of Medicine, University of São Paulo (USP), São Paulo, Brazil \\ Email: prisciladib@gmail.com
}

Received November 29, 2013; revised December 28, 2013; accepted January 9, 2014

Copyright (c) 2014 Priscila Dib Gonçalves et al. This is an open access article distributed under the Creative Commons Attribution License, which permits unrestricted use, distribution, and reproduction in any medium, provided the original work is properly cited. In accordance of the Creative Commons Attribution License all Copyrights (C) 2014 are reserved for SCIRP and the owner of the intellectual property Priscila Dib Gonçalves et al. All Copyright (c) 2014 are guarded by law and by SCIRP as a guardian.

\begin{abstract}
Introduction: Executive Dysfunction (ED) is associated with difficulties in daily life and poor treatment adherence in individuals with neurological and psychiatric disorders. The aim of this paper is to present an update of Executive Function (EF) Rehabilitation Techniques. Methods: We performed a comprehensive literature review using the following keywords: executive function, mental disorders and rehabilitation in the PubMed, specific journals and books. Results: There is evidence of improvement of EF using some rehabilitation techniques, such as goal planning, goal management training, problem solving training, verbalization, drill and practice approach, metacognitive strategy instruction, computer-assisted training and neurofeedback. However, impact of rehabilitation on daily life remains poorly understood. Conclusion: Executive Dysfunction (ED) may be remediated and/or compensated at a certain degree by neuropsychological rehabilitation, but there is still a great challenge in this area based on how to measure effectiveness of EF interventions on daily life. There is a need for the development of new and/or combined techniques (i.e., pharmacological treatment, deep-brain stimulation) for a broader impact on quality of life for patients.
\end{abstract}

\section{KEYWORDS}

Rehabilitation; Neuropsychology; Executive Functions and Board Games

\section{Introduction}

Psychiatric Disorders affect 450 million people and their costs to society represent a significant impact on the total Disability Adjust Life Years (DALYs) of all diseases in the world [1]. One of the main causes of disability in psychiatric disorders is associated with deficits in Executive Functions, a very common cognitive abnormality related to frontal or diffuse brain alterations typically seen in these patients. The Executive Functions (EFs) are intrinsic to the ability to respond in an adaptive manner to new situations and they are also the basis for many cognitive, emotional and social skills. The EF is divided into volition, planning, purposive action and effective performance [2].

Executive Dysfunction (ED) in Traumatic Brain Injury (TBI) is associated with a persistent loss of social autonomy and inability to return to work [3]. The nature of these deficits, such as poor ability to criticize, distractibility, difficulty in abstract thinking, can compromise the patient's ability and motivation to adapt strategically to his/her disabilities [4]. Psychiatric and neurological patients with ED have independence and participation in 
affected activities, especially in daily life activities [5], moreover, they are more likely to drop out from treatment [6].

However, pharmacological interventions do not completely remediate cognitive deficits and even secondgeneration antipsychotics have a modest beneficial effect on cognition in schizophrenia [7,8]. Therefore, nonpharmacological intervention such as neuropsychological rehabilitation may be useful to improve EF. Moreover, we believe the reduction of these deficits could significantly improve these patients' emotional health, social functioning and independence skills, decreasing illness burdens and other expenses [8]. Neuropsychological rehabilitation (NR) focuses on empowering people affected by cognitive deficits, emotional and behavioral disorders to achieve their maximum potential in psychological, social, recreational and vocational areas, as well as in their daily functioning. The first step in order to plan an appropriate intervention program is to map the neuropsychological functioning, aiming to investigate the patient's cognitive strengths and weaknesses [9].

It is relevant to review studies in this topic considering the rare number of investigations that focus on NR of EF in psychiatric patients. In the history of neuropsychology, it is common to notice an adaptation of techniques used in neurological disorders to psychiatric patients. In addition, it is difficult to establish a clear overview about the NR techniques and their effectiveness, due to the complexity of the EF. The aim of this paper is to present an update of techniques and NR models used in neurological and psychiatric patients, in order to provide a theoretical background to discuss about the NR of psychiatric patients with ED.

\section{Methods}

We performed a comprehensive literature review using the following keywords: executive function, mental disorders and rehabilitation in a database (PubMed), specific journals and books which were published until December 2012. Our search methods resulted on 57 published articles plus articles from the references according to the relevance of the key words. We only included articles about psychiatric disorders and/or TBI and NR. After that, 36 articles were excluded because of their topics were related to: prevalence, type and severity of cognitive deficits, gender differences in EF after TBI, adaptation and/or validation of neuropsychological tests, neuropsychological profile and/or performance, biopsychosocial deconstruction of "personality change" following acquired brain injury, changes in cognition though aging, executive functions in the prediction of mortality in the elderly, peer-relationship difficulties in children with brain injuries, kidney transplant recipients, elderly patients with type 2 diabetes mellitus, mechanism of anosognosia after stroke, memory functions, employment, unemployment, autism, ecological test in schizophrenia and children with attention deficit hyperactivity disorder. We also decided to exclude 8 articles about techniques that stimulate not only EF but also other cognitive and social functions (i.e., articles focusing on theory of mind, social cognition, emotion recognition, cognitive behavior therapy, aerobic exercises).

\section{Results}

There were thirteen articles selected, which are briefly presented below (Table 1 ).

For didactic purposes, the articles were classified in two groups, considering the EF theoretical model of Lezak et al. [2]: rehabilitation of volition and planning, and technics that improve purposive action and effective performance.

A neuropsychological evaluation plays an important role to guide treatment for it is a way to investigate which cognitive abilities are intact and which ones have been impaired and how impaired they are [10].

First Group: Rehabilitation of volition and planning in patients with ECF impairments.

Volition is the capacity for intentional behavior (to formulate a goal or to form an intention) that includes motivation, self-awareness, social awareness, awareness of one's physical status, of the environment and the situational context. Planning refers to the identification and organization of the steps and elements needed to carry out an intention and achieve a goal [2]. The organization of directed behavior, which is related to frontal functions, relies on the selection of sequential actions; not surprisingly frontal lesion patients often present goal neglect (disregard of a task requirement even though it has been understood and remembered) [11]. Goals, a desired or expected future state [12], are essential in the rehabilitation process as they may enable the patient to return to the environment and to his/her normal life [9]. A goal should be Specific, Measurable, Achievable, Realistic/ relevant and Timed (SMART) [13]. As goal setting is the core of the NR process, it is necessary to include the patients and all involved members (such as family and staff) in it [12]. For example, in a TBI case report, the goals were: to explain consequences of brain injuries and their impact on daily life, reduction of intrusive thoughts, to use memory systems and planning for independent living activities, to use strategies for sustained attention in daily activities [9].

The Goal Management Training (GMT) [14] is composed of 5 stages: orientation, goal selection, definition of sub-goals to achieve the main goal, memorize the sub-goals and outcome. These structured exercises encourage the patients to monitor and evaluate their own performance in situations of everyday life. For example, 
Table 1. Articles about neuropsychological rehabilitation of Executive Function (EF).

\begin{tabular}{|c|c|c|c|c|}
\hline Authors/year & Sample & Technique & Duration & Results \\
\hline Ducan et al. /1996 [11] & Frontal patients & - & - & Goal neglect is related to frontal functions deficits. \\
\hline Wade/1998 [12] & Health care & Goal Planning & - & Goal Planning was beneficial in the used setting. \\
\hline Levine et al. /2000 [14] & TBI $(n=30)$ & GAT & 4 to 6 sessions & Improvement daily life outcome measures. \\
\hline Levine et al./2000 [14] & $\begin{array}{l}\text { Meningoencephalitis } \\
\text { (case report) }\end{array}$ & GAT & 13 sessions & $\begin{array}{l}\text { Less difficulty in a cooking task after the } \\
\text { intervention and in the 3-month follow up. }\end{array}$ \\
\hline Von Cramon et al. /1991 [15] & $\begin{array}{l}\text { Brain damage } \\
\qquad(\mathrm{n}=37)\end{array}$ & PST $(n=20)$ & 25 sessions & Improvements on problem solving tasks. \\
\hline $\begin{array}{l}\text { Miotto et al./2010 } \\
\text { [17] }\end{array}$ & $\begin{array}{l}\text { Frontal lobes } \\
\text { lesions }(n=30)\end{array}$ & Attention \& PSA & 10 sessions & $\begin{array}{l}\text { Improvement of the ability to manage novel } \\
\text { real life situation tasks. }\end{array}$ \\
\hline Harvey et al./2010 [20] & $\begin{array}{l}\text { Schizophrenia } \\
\qquad(\mathrm{n}=22)\end{array}$ & Verbali-zing & 1 test session & $\begin{array}{l}\text { When performing multiple stimuli tasks } \\
\text { verbalization was effective. }\end{array}$ \\
\hline Couillet et al. /2010 [23] & TBI $(\mathrm{n}=12)$ & $\begin{array}{l}\text { Simulation of } \\
\text { daily life tasks }\end{array}$ & 24 sessions & $\begin{array}{l}\text { Simulation of daily life tasks presented an } \\
\text { improvement on divided attention. }\end{array}$ \\
\hline $\begin{array}{l}\text { Spikman et al./2010 } \\
\text { [24] }\end{array}$ & Acquired Brain Injury & Multi-faceted treatment & $\begin{array}{c}20-24 \\
\text { sessions }\end{array}$ & $\begin{array}{c}\text { Experimental group presented an Improvement } \\
\text { on social participation and on Treatment } \\
\text { Goal Attainment }\end{array}$ \\
\hline Kuhn et al./2011 [32] & $\begin{array}{l}\text { Alcohol dependent } \\
\qquad(\mathrm{n}=1)\end{array}$ & $\begin{array}{l}\text { Deep brain stimulation of } \\
\text { the nucleus accumbens } \\
\text { Brain training }\end{array}$ & - & $\begin{array}{l}\text { Positive effect on addiction trough a } \\
\text { normalization of the craving associated with } \\
\text { anterior midcingulate cortex }\end{array}$ \\
\hline $\begin{array}{l}\text { Rabipour et al./2012 } \\
\text { [19] }\end{array}$ & $\begin{array}{l}\text { Cognitively impaired } \\
\text { individuals }\end{array}$ & $\begin{array}{l}\text { Cognitive remediation } \\
\text { therapy }\end{array}$ & - & $\begin{array}{l}\text { Enhacing performance on conflict and } \\
\text { inhibition tasks and decreasing reports } \\
\text { symptoms related to the disorder }\end{array}$ \\
\hline $\begin{array}{l}\text { Rupp et al./2012 } \\
{[18]}\end{array}$ & $\begin{array}{l}\text { Alcohol dependent } \\
\text { patients } \\
(\mathrm{n}=41)\end{array}$ & - & - & $\begin{array}{l}\text { Improvement in attention/executive } \\
\text { functions, memory, psychological well-being } \\
\text { and in the compulsion aspects of craving }\end{array}$ \\
\hline $\begin{array}{l}\text { Milioni } \\
\text { et al./2013 } \\
\quad[10]\end{array}$ & TBI & - & 12 sessions & $\begin{array}{l}\text { All the valid strategies to be adopted after TBI } \\
\text { must include an integration of behavioral, familiar, } \\
\text { educational and pharmacological approaches }\end{array}$ \\
\hline
\end{tabular}

Note: GAS = Goal Attainment Scaling. GAT = Goal Management Training. MT = memory training. MSI = Metacognitive Strategy Instruction. PST = problem-solving training. PSA = Problem Solving Approach. SMART refers to a goal that should be Specific, Measurable, Achievable, Realistic/relevant and Timed. TBI = Traumatic Brain Injury.

the strategies that include a break in activities aimed at stopping and thinking, breaking goals into sub-goals by making them more manageable, using mental images and to-do lists. The overall goal is to help individuals identify what works best for them, and promote the implementation of these strategies in everyday situations. Levine et al. [14] compared GMT to motor skills training (MST); their results showed that GMT was related to performance improvement on outcome measures similar to daily life activities. The GMT also had good results in a case of meningo-encephalitis with executive dysfunction, which reported less difficulty in preparing meals, with long-term gains.

The problem-solving training is another technique that also uses teaching strategies and steps. This technique is the replacement of patient's impulsive approach for verbal systematic analyses of goals and means to achieve them. Patients are encouraged to: identify the problem, separate relevant from irrelevant information, draw connections between the relevant items, generate possible solutions and monitor their effectiveness [15-17]. The use of problem-solving training has proved very useful in a study with TBI patients with ED: the patients submitted to this training showed improvements in planning tasks and in the therapist's assessments of everyday behavior [15].

According to a study by Rupp et al. [18], cognitive remediation through 12 individual computer-assisted training sessions showed significant improvements on alcohol-related impairments in purposive attention, function and memory, specifically alertness, divided attention, working memory and delayed memory. Despite incremental benefit for some specific alcohol-related cognitive impairments, the results suggest that they are not for all aspect of cognitive functioning, such as inhibitory control. There are some limitations in this study such as 
the modest number of subjects (41 patients; 20 of them in the control group and the other 21 in the cognitive remediation group) and the fact that control group patients were not exposed to a computer and the improvements may have been merely attributable to placebo effect.

Neurofeedback training is a computerized technique that trains individuals to actively control and change their neural activation patterns by viewing the brainwaves they emit after occurring. Rabipour et al. [19] in their study, advertise the improvement in mental functioning and increase of awareness. Nevertheless, it is still necessary to investigate the sustainability of these effects.

Miotto et al. [17] conducted a study with thirty patients presenting frontal lobe lesions using the attention and problem solving approach, which merges two techniques already described (GMT and problem-solving training). This approach is composed of three stages: problem awareness, monitoring and evaluation, and developing, initiating and implementing a plan. Their findings demonstrated improvement in EF ecological measures, symptoms evaluation and real-life activities.

Second Group: How to maintain a purposive action and effective performance in patients with ECF impairments.

Purposive action is the translation of an intention or plan into productive, self-serving activity and involves the ability to: initiate, maintain, switch, and stop sequences of complex behavior in an orderly and integrated manner. Effective performance corresponds to the ability of self-monitoring [2].

The treatment will vary depending on individual deficits. The restorative approach is focused on reinforcing the functions that remains at least some extent intact. The compensatory approach focuses on training the patients on new strategies to cope with the impairment [10].

Some patients present difficulties in accomplishing actions, despite of presenting preservation of planning skills. One cognitive strategy used to improve this difficulty is verbalization, (speaking out loud, describing the steps of what one individual is doing while undertaking tasks). A study revealed that verbalization could improve the performance on activities, which involves various EF elements in schizophrenic patients especially on multiple EF tasks [20].

A review on 15 studies of interventions after TBI (focusing on the improvement of everyday problem solving, planning, organization and multi-tasking) showed that the most used techniques were: training multiple steps (including metacognitive strategy instruction), training strategic thinking, and training multitasking. In most studies, treatment was individual and the average treatment time was about12 hours. All studies reported positive results after treatment (qualitative and quantitative analysis) [21].

Metacognitive strategy instruction (MSI) can be ano- ther effective cognitive strategy. This approach uses instructions to teach people how to self-monitor through identification of appropriate goals and performance prediction in an activity in advance. The participants try to identify possible solutions based on: general predictions (which could be based on past experiences), self-monitoring or evaluation of performance during an activity, and behavior change in choosing a strategy. For example: ask the patient to predict his/her performance on the next trial, ask him/her to analyzed previous performance [21,22].

A randomized trial with TBI patients has presented improvement on psychometric measures and on everydaylife scales. This rehabilitation program of divided attention showed that experimental training (tasks close to patients daily life: cooking, simulation of daily life situations, summarizing news) when compared to control training (vigilance or simple visual search tasks and simple problem solving) had particular effect on divided attention, which enabled patients to respond faster and more precisely when performing tasks with multiple stimulus [23].

A prospective multicenter randomized control trial with acquired brain injury patients using the Multifaceted Treatment of Executive Dysfunction approach, which is based on Ylvisaker's conceptual framework (self-awareness, goal-setting, planning, self-initiation, self-monitoring, self-inhibition, flexibility, and strategic behavior), showed treatment effects on outcome measures related to daily life executive functioning after intervention and also lasting for 6 months after treatment [24].

It was found that family can interfere with the success of the treatment. The collaboration in many areas such as transportation, finances and emotional support can be associated to successful rehabilitation results [10]. Nevertheless, emotional distress and family dysfunction may difficult or impede the recovery process because of the patient vulnerability.

However, there are several limitations in previous studies (see Table 1), such as several types of methodology (i.e. each study has a different number of sessions), few of instruments to measure EF rehabilitation effectiveness, lack of control group, lack of generalization of their findings in real life and absence of follow-up studies investigating the maintenance of rehabilitation effects. These factors may not only significantly limit the comparability of data and results among studies, but also overestimate possible positive effects of NR (resulting in false-positive effects of NR). Further research would help us to establish a greater degree of accuracy in Neuropsychological Rehabilitation.

In sum, there is a need for the development of new tools to stimulate EF in neurological and psychiatric patients. This represents an actual challenge for the rehabilitation of ED. Recently, we found that the use of board games, especially chess, seems to be a promising tech- 
nique. As games require strategy development and problem solving, they tend to facilitates cognitive and affective self-regulation. Games can promote a great motivation of the participants, due to their association with real-life issues and not with artificial or experimental materials [9]. Thus, the interaction with the other player stimulates self-monitoring, as the strategies and the moves are influenced by external stimuli. In fact, Prigatano et al. [25] stated that the NR success is related to programs, which focus not only on cognitive functions but also on subjective aspects (emotions and motivation). Moreover, it was observed through functional neuroimaging greater activation in the prefrontal cortex area during this game [26,27]. Games have rules that are shared with others, and this process of being submitted to the rules enables the development of cognitive and social skills [28]. Board games were already used to improve cognitive functioning with stimulating results [29,30]. Moreover our preliminary study with substance dependents showed a reduction on impulsivity and working memory with chess game demonstrating the feasibility of this tool in the neuropsychological rehabilitation [31]. Efficacy studies should be performed to verify the effects of cognitive stimulation in improving executive functioning of patients and in the process of relapse prevention.

Another possibility is to combine neuropsychological rehabilitation with pharmacological interventions, such as Stimulants (i.e., methylphenidate), focusing on dopamine pathways aiming to reduce attention and executive dysfunction in patients with EF [10]. Other very interesting technique refer to the Deep brain stimulation of the nucleus accumbens, which has been related to changes in performance monitoring and craving in severe alcohol dependence by increasing impulse control and decision making [32].

\section{Conclusion}

The traditional rehabilitation techniques show some improvements in EF. In this review, we analyzed data about several strategies such as goal planning, writing SMART goals, goal management training, problem solving training, attention and problem solving approach, verbalization, strategy-based approach, drill and practice approach, metacognitive strategy instruction, simulation of daily life tasks and multifaceted treatment program for executive dysfunction, neurofeedback, and computer-assisted training. In general, it seems that there is no consensus about a unique approach for EF rehabilitation. Besides that, new strategies must be developed and board games could be a highly promising therapeutic tool, which can be easily used in any social economical level. Combined strategies considering neuropsychological rehabilitation techniques, pharmacological treatment and deep-brain stimulation could also have a more significant impact on
EF, but only future prospective studies could investigate the efficacy and the impact on patient's daily routine of such interventions. At last, new studies should investigate other factors and their influence on cognitive rehabilitation.

\section{REFERENCES}

[1] World Health Organization, "Prevention of Mental Disorders: Effective Interventions and Policy Options: A Summary Report,” 2004.

[2] M. Lezak, D. Howieson, D. Loring, H. Hannay and J. Fischer, "Neuropsychological Assessment," Oxford University Press, New York, 2004.

[3] J. M. Mazaux, F. Masson, H. S. Levin, P. Alaoui, P. Maurette and M. Barat, "Long-Term Neuropsychological Outcome and Loss of Social Autonomy after Traumatic Brain Injury," Archives of Physical Medicine and Rehabilitation, Vol. 78, No. 12, 1997, pp. 1316-1320. http://dx.doi.org/10.1016/S0003-9993(97)90303-8

[4] J. Fish, J. J. Evans, M. Nimmo, E. Martin, D. Kersel, A. Bateman, B. A. Wilson and T. Manly, "Rehabilitation of Executive Dysfunction Following Brain Injury: 'ContentFree' Cueing Improves Everyday Prospective Memory Performance,” Neuropsychologia, Vol. 45, No. 6, 2007, 1318-1330.

http://dx.doi.org/10.1016/j.neuropsychologia.2006.09.015

[5] N. Josman, A. E. Schenirderman, E. Klinger and E. Shevil, "Using Virtual Reality to Evaluate Executive Functioning among Persons with Schizophrenia: A Validity Study,” Schizophrenia Research, Vol. 115, No. 2-3, 2009, pp. 270-277.

http://dx.doi.org/10.1016/j.schres.2009.09.015

[6] E. Aharonovich, P. C. Amrhein, A. Bisaga, E. V. Nunes and D. S. Hasin, "Cognition, Commitment Language, and Behavioral Change among Cocaine-Dependent Patients," Psychology of Addictive Behaviors, Vol. 22, No. 4, 2008, pp. 557-562. http://dx.doi.org/10.1037/a0012971

[7] N. D. Woodward, S. E. Purdon, H. Y. Meltzer and D. H. Zald, “A Meta-Analysis of Neuropsychological Change to Clozapine, Olanzapine, Quetiapine, and Risperidone in Schizophrenia," The International Journal of Neuropsychopharmacology, Vol. 8, No. 3, 2005, pp. 457-472. http://dx.doi.org/10.1017/S146114570500516X

[8] S. K. Hill, J. R. Bishop, D. Palumbo and J. A. Sweeney, "Effect of Second-Generation Antipsychotics on Cognition: Current Issues and Future Challenges," Expert Review of Neurotherapeutics, Vol. 10, No. 1, 2010, pp. 4357. http://dx.doi.org/10.1586/ern.09.143

[9] B Wilson, F Gracey, J Evans and A. Bateman, "Neuropsychological Rehabilitation: Theories, Models, Therapy and Outcome," Cambridge University Press, Cambridge, 2009. http://dx.doi.org/10.1017/CBO9780511581083

[10] A. Milioni, P. Rodrigues and P. Cunha, "Cognitive Functioning and Prefrontal Cortex Demage in Children and Adolescents: Consequences, Rehabilitation and Neural Plasticity,” In: O. Collins and J. Adams, Eds., Prefrontal Cortex: Developmental Differences, Executive and Cognitive Functions and Role in Neurological Disorders, 
Nova Biomedical, Waltham, 2013.

[11] J. Duncan, H. Emslie, P. Williams, R. Johnson and C. Freer, "Intelligence and the Frontal Lobe: The Organization of Goal-Directed Behavior," Cognitive Psychology, Vol. 30, No. 3, 1996, pp. 257-303. http://dx.doi.org/10.1006/cogp.1996.0008

[12] D. T. Wade, "Evidence Relating to Goal Planning in Rehabilitation,” Clinical Rehabilitation, Vol. 12, No. 4, 1998, pp. 273-275. http://dx.doi.org/10.1191/026921598678166365

[13] T. J. Bovend'Eerdt, R. E. Botell and D. T. Wade, "Writing SMART Rehabilitation Goals and Achieving Goal Attainment Scaling: A Practical Guide,” Clinical Rehabilitation, Vol. 23, No. 4, 2009, pp. 352-361. http://dx.doi.org/10.1177/0269215508101741

[14] B. Levine, I. H. Robertson, L. Clare, G. Carter, J. Hong, B. A. Wilson, J. Duncan and D. T. Stuss, "Rehabilitation of Executive Functioning: An Experimental-Clinical Validation of Goal Management Training," Journal of the International Neuropsychological Society, Vol. 6, No. 3, 2000, pp. 299-312. http://dx.doi.org/10.1017/S1355617700633052

[15] D. Y. Von Cramon, G. Matthes-von Cramona and N. Mai, "Problem-Solving Deficits in Brain-Injured Patients: A Therapeutic Approach,” Neuropsychol Rehabil, Vol. 1, No. 1, 1991, pp. 45-64.

http://dx.doi.org/10.1080/09602019108401379

[16] T. Manly, K. Hawkins, J. Evans, K. Woldt and I. H. Robertson, "Rehabilitation of Executive Function: Facilitation of Effective Goal Management on Complex Tasks Using Periodic Auditory Alerts,” Neuropsychologia, Vol. 40, No. 3, 2002, pp. 271-281. http://dx.doi.org/10.1016/S0028-3932(01)00094-X

[17] E. C. Miotto, J. J. Evans, M. C. de Lucia and M. Scaff, "Rehabilitation of Executive Dysfunction: A Controlled Trial of an Attention and Problem Solving Treatment Group,” Neuropsychological Rehabilitation, Vol. 19, No. 4, 2009, pp. 517-540. http://dx.doi.org/10.1080/09602010802332108

[18] C. Rupp, G. Kemmler, M. Kurz, H. Hinterhuber and W. Fleischhacker, "Cognitive Remediation during Treatment for Alcohol Dependence,” 2012.

[19] S. Rabipour and A. Raz, "Training the Brain: Fact and Fad in Cognitive and Behavioral Remediation," Brain and Cognition, Vol. 79, No. 2, 2012, pp. 159-179. http://dx.doi.org/10.1016/j.bandc.2012.02.006

[20] K. E. Harvey, C. A. Galletly, C. Field and M. Proeve, "The Effects of Verbalisation on Cognitive Performance in Schizophrenia: A Pilot Study Using Tasks from the Delis Kaplan Executive Function System,” Neuropsychological Rehabilitation, Vol. 19, No. 5, 2009, pp. 733-741. http://dx.doi.org/10.1080/09602010902732892

[21] M. R. Kennedy, C. Coelho, L. Turkstra, M. Ylvisaker, M. Moore Sohlberg, K. Yorkston, H. H. Chiou and P. F. Kan, "Intervention for Executive Functions after Traumatic Brain Injury: A Systematic Review, Meta-Analysis and Clinical Recommendations," Neuropsychological Rehabilitation, Vol. 18, No. 3, 2008, pp. 257-299.

http://dx.doi.org/10.1080/09602010701748644
[22] M. M. Sohlberg, L. Ehlhardt and M. Kennedy, "Instructional Techniques in Cognitive Rehabilitation: A Preliminary Report,” Semin Speech Lang, Vol. 26, No. 4, 2005, pp. 268-279. http://dx.doi.org/10.1055/s-2005-922105

[23] J. Couillet, S. Soury, G. Lebornec, S. Asloun, P. A. Joseph, J. M. Mazaux and P. Azouvi, "Rehabilitation of Divided Attention after Severe Traumatic Brain Injury: A Randomised Trial," Neuropsychological Rehabilitation, Vol. 20, No. 3, 2010, pp. 321-339. http://dx.doi.org/10.1080/09602010903467746

[24] J. M. Spikman, D. H. Boelen, K. F. Lamberts, W. H. Brouwer and L. Fasotti, "Effects of a Multifaceted Treatment Program for Executive Dysfunction after Acquired Brain Injury on Indications of Executive Functioning in Daily Life," Journal of the International Neuropsychological Society, Vol. 16, No. 1, 2010, pp. 118-129. http://dx.doi.org/10.1136/jnnp.47.5.505

[25] G. P. Prigatano, D. J. Fordyce, H. K. Zeiner, J. R. Roueche, M. Pepping and B. C. Wood, "Neuropsychological Rehabilitation after Closed Head Injury in Young Adults," Journal of Neurology, Neurosurgery \& Psychiatry, Vol. 47, No. 5, 1984, pp. 505-513. http://dx.doi.org/10.1136/jnnp.47.5.505

[26] M. Atherton, J. Zhuang, W. M. Bart, X. Hu and S. He, “A Functional MRI Study of High-Level Cognition. I. The Game of Chess,” Cognitive Brain Research, Vol. 16, No. 1, 2003, pp. 26-31. http://dx.doi.org/10.1016/S0926-6410(02)00207-0

[27] P. Nichelli, J. Grafman, P. Pietrini, D. Alway, J. C. Carton and R. Miletich, "Brain Activity in Chess Playing," Nature, Vol. 369, No. 6477, 1994, p. 191. http://dx.doi.org/10.1038/369191a0

[28] V. Oliveira, “Jogos de Regras e Resoluções e Problemas,” Vozes, Petrópolis, 2004.

[29] C. Demily and N. Franck, "Cognitive Remediation: A Promising Tool for the Treatment of Schizophrenia,” Expert Review of Neurotherapeutics, Vol. 8, No. 7, 2008, pp. 1029-1036. http://dx.doi.org/10.1586/14737175.8.7.1029

[30] C. Demily, C. Cavezian, M. Desmurget, M. BerquandMerle, V. Chambon and N. Franck, "The Game of Chess Enhances Cognitive Abilities in Schizophrenia,” Schizophrenia Research, Vol. 107, No. 1, 2009, pp. 112-113. http://dx.doi.org/10.1016/j.schres.2008.09.024

[31] P. D. Gonçalves, M. Ometto, A. Bechara, A. Malbergier, R. Amaral, S. Nicastri, P. Martins, L. Beraldo, B. Santos, D. Fuentes, A. G. Andrade, G. Busatto and P. J. Cunha, "Motivational Interviewing Combined with Chess Accelerates Improvement in Executive Functions in Cocaine Dependent Patients: A One-Month Prospective Study,” in Preparation.

[32] J. Kuhn, T. Gründler, R. Bauer, W. Huff, A. Fischer, D. Lenartz, M. Maarouf, C. Bührle, J. Klosterkötter, M. Ullsperger and V. Sturm, "Successful Deep Brain Stimulation of the Nucleus Accumbens in Severe Alcohol Dependence is Associated with Changed Performance Monitoring," Addiction Biology, Vol. 16, No. 4, 2011, pp. 620623. http://dx.doi.org/10.1111/j.1369-1600.2011.00337.x 